\title{
PEMANFAATAN DATA SATELIT HIMAWARI 8 UNTUK MENDETEKSI SEBARAN ASAP: STUDI KASUS DI KALIMANTAN DAN SUMATERA TANGGAL 8 DAN 9 SEPTEMBER 2015
}

\author{
Ayu Vista Wulandari ${ }^{1, a)}$, Ni Kadek Trisna Dewi ${ }^{1, b)}$, Wishnu Agum Swastiko ${ }^{1, c)}$ \\ ${ }^{1)}$ Sekolah Tinggi Meteorologi Klimatologi dan Geofisika \\ Jl. Perhubungan I no 5, Pondok Betung, Pondok Aren, Tangerang Selatan,
} Banten 15221

Email: a) ayu.vista10@gmail.com, ${ }^{\text {b) }}$ nikadktrisnadewi@gmail.com, ${ }^{\mathrm{c}}$ wswastiko@ gmail.com

\begin{abstract}
Abstrak
Kebakaran hutan yang terjadi di sepanjang bulan September 2015 dirasa cukup menganggu aktivitas masyarakat di wilayah Kalimantan dan Sumatera. Kabut asap yang timbul akibat kebakaran hutan memiliki dampak negatif bagi lingkungan sekitar, salah satunya berkurangnya jarak pandang mendatar (visibility). Stasiun Meteorologi di wilayah Kalimantan dan Sumatera mencatat visibility terendah terjadi pada tanggal 8 dan 9 September 2015 yaitu rata-rata mencapai $100 \mathrm{~m}$. Berdasarkan informasi BMKG (Badan Meteorologi Klimatologi dan Geofisika) diketahui bahwa pada bulan September 2015 terjadi sebaran hotspot yang merupakan indikasi terjadinya kasus kebakaran hutan tersebut. Penulisan ini dilakukan untuk mengetahui potensi sebaran asap melalui citra satelit Himawari 8 untuk mengurangi dampak buruk sebaran asap tersebut. Metode yang dilakukan yaitu dengan membandingkan data sebaran hotspot BMKG dengan hasil citra RGB false colour (1 kanal visible dan 2 kanal near infrared) dan trajektori sebaran asap dengan memanfaatkan aplikasi SATAID GMSLPD. Hasil penelitian menunjukkan bahwa lokasi sebaran asap melalui citra RGB dan data hotspot BMKG menunjukkan kesesuaian wilayah yang dominan tertutupi asap yaitu di wilayah bagian barat Sumatera dan bagian tengah Kalimantan. Dapat diasumsikan bahwa penggunaan citra satelit Himawari 8 dianggap cukup mampu untuk mendeteksi sebaran asap akibat kebakaran hutan yang terjadi.
\end{abstract}

Kata-kata kunci: Asap, Satelit, Himawari 8, SATAID.

\begin{abstract}
The forest fires that occurred in the entire month of September 2015 was quite considerably disturbing many public activities in Borneo and Sumatera. The smoke which is caused by forest fire have negative impacts for the surrounding environments, one of them is reducing horizontal visibility. Meteorological stations in Borneo and Sumatra recorded the lowest visibility occurred in September, 8th and 9th 2015 at average range was $100 \mathrm{~m}$. Based on BMKG information (Indonesian Agency of Meteorological, Climatological and Geophysics) noted that during the month of September 2015 there was a distribution of hotspots which indicates the occurrence of forest fire cases. This research is aimed to determine the potential of distribution of smoke by satellite imagery of Himawari 8 to reduce its negative impacts. By using this method that is by comparing the hotspot distribution data from BMKG with false color RGB image product (1 visible channel and 2 near infrared channel) along with the trajectory of smoke's distribution by utilizing application of GMSLPD SATAID. The distribution of smoke can be seen as an image with the brownish pattern which partially covered the area of Borneo and Sumatera. The result showed that the smoke's distribution by the result of RGB imagery well-matched enough with the hotspot's distribution data from BMKG, which the smoke almost covered most areas of the western of
\end{abstract}


Sumatera and center of Borneo. In this case also supported by the trajectory of smoke's distribution which is derived from the southeast-south and spread to the northwest-north in the research area. By using the observed data from choosing meteorological stations showed a similar result with the above method. Thus, it can be assumed that by using satellite imagery of Himawari 8 is quite capable to discover the smoke's distribution caused by the forest fire case.

Keywords: Smoke, Satellite, Himawari 8, SATAID.

\section{PENDAHULUAN}

Indonesia merupakan negara yang berada di wilayah tropis dengan kawasan hutan yang hampir merata di setiap provinsi. Hutan merupakan salah satu aspek biosfer bumi yang paling penting karena hutan adalah bentuk kehidupan yang tersebar di dunia sebagai penghasil oksigen, penyedia sumber air, tempat hidup berbagai flora dan fauna, sekaligus memiliki peran penyeimbang lingkungan. Kebakaran hutan dan lahan adalah bencana yang sering berulang terjadi setiap tahun di wilayah Indonesia mulai dari jaman pra kemerdekaan hingga pasca kemerdekaan [2]. Periode bulan terjadinya kebakaran hutan dan lahan di Indonesia biasanya terjadi pada musim kemarau, yaitu pada bulan Agustus, September, dan Oktober, maupun pada masa peralihan atau transisi $[1,6,8]$.

Kebakaran hutan merupakan fenomena alam yang berpotensi menimbulkan kerusakan di beberapa wilayah Indonesia, terutama di wilayah Sumatera dan Kalimantan. Berdasarkan informasi dari Badan Nasional Penanggulangan Bencana (BNPB), titik hotspot terbanyak terdapat pada bulan September 2015 yang terjadi di wilayah Sumatera dan Kalimantan. Menurut Stasiun Meteorologi milik Badan Meteorologi Klimatologi dan Geofisika (BMKG) yang terdapat di wilayah Sumatera dan Kalimantan, kebakaran hutan berdampak terhadap menurunnya jarak pandang mendatar (horizontal visibility). Berdasarkan data observasi sinoptik, visibility mencapai $100 \mathrm{~m}$ yang terjadi pada tanggal 8 dan 9 September 2015. Rendahnya visibility menimbulkan beberapa kerugian bagi masyarakat khususnya di sektor transportasi. Selain hal tersebut, asap dari kebakaran hutan juga berdampak buruk bagi kesehatan masyarakat.

Penelitian ini difokuskan untuk mengetahui sebaran asap melalui citra satelit Himawari 8 dengan memanfaatkan metode Red Green Blue (RGB) dan mengetahui trajektori arah sebaran asap dengan menggunakan aplikasi SATAID (Satellite Animation and Interactive Diagnosis) pada saat terjadi kebakaran hutan di wilayah Sumatera dan Kalimantan pada tanggal 8 dan 9 September 2015. Penulis berharap agar dengan kemajuan teknologi dan ilmu pengetahuan saat ini mampu memudahkan masyarakat dalam memantau dan mengetahui penyebaran asap akibat kebakaran hutan dan lahan, yaitu salah satunya dengan memanfaatkan dan mengenali satelit cuaca.

\section{METODE PENELITIAN}

Data yang digunakan dalam penelitian ini terdiri dari:

- Data satelit Himawari 8 kanal $3(0.64 \mu \mathrm{m})$, kanal $4(0.86 \mu \mathrm{m})$, dan kanal $6(2.3 \mu \mathrm{m})$ pada tanggal 8-9 September 2015

- Data model GS tanggal 8-9 September 2015

- Data hotspot di Sumatera dan Kalimantan tanggal 8-9 September 2015.

Penelitian ini memanfatkan data dari satelit Himawari 8 yang diolah menggunakan aplikasi SATAID GMSLPD untuk menghasilkan kombinasi RGB citra satelit dari kanal 3,4, dan 6. Himawari 8 merupakan generasi baru dari satelit himawari sebagai pengganti seri satelit MTSAT (Multifunctional Transport Sattelites) yang dikembangkan oleh Japan Meteorology Agency (JMA), yang secara umum bertujuan untuk menjaga kesinambungan dan meningkatkan pengamatan cuaca dalam rangka pencegahan bencana dan ramalan cuaca, meningkatkan kemampuan ramalan jangka pendek terutama untuk deteksi dan prediksi cuaca buruk, meningkatkan akurasi prediksi cuaca numerik, serta meningkatkan pemantauan iklim dan lingkungan [3]. Aplikasi SATAID berfungsi untuk menampilkan gambar dan data dari parameter meteorologi dari citra satelit Himawari 8. 
Metode RGB merupakan teknik untuk menampilkan gambar dengan mengkombinasikan tiga warna primer (merah, hijau, dan biru). Kombinasi dari 3 warna primer tersebut akan menghasilkan warna-warna turunan seperti kuning, magenta,cyan, cokelat, hitam, dan putih [7]. Pengolahan data citra satelit dengan menggunakan metode RGB ini adalah dengan menggabungkan tiap kanal yang berbeda untuk mendapatkan suatu produk citra yang berisikan tentang informasi yang dikaji.

Adapun langkah-langkah kerja untuk menampilkan citra satelit RGB adalah sebagai berikut:

- Menampilkan tiga jenis citra satelit Himawari 8 kanal 3,4, dan 6 untuk tanggal 8-9 September 2015 pada aplikasi SATAID GMSLPD.

- Mengaktifkan function gray pada kanal 3 citra satelit Himawari 8 untuk mengatur kombinasi warna RGB pada citra.

- Mengatur ketiga kanal citra satelit dengan kanal 3 sebagai image pertama dengan warna merah (nilai gamma 1.8), kanal 4 sebagai image kedua dengan warna hijau (nilai gamma 1.0), dan kanal 6 sebagai image ketiga dengan warna biru (nilai gamma 3.0)

- Menyimpan hasil olahan dengan format .jpg

Setelah melakukan olahan dengan metode RGB, dilanjutkan dengan menampilkan trajektori sebaran asap untuk mengetahui prediksi arah sebaran asap dengan mengoverlay data model dengan data citra satelit. Berikut langkah-langkah kerja:

- Mengoverlay data model dengan data citra satelit melalui menu Register, kemudian pilih GS

- Mengaktifkan function NWP untuk tampilan data model pada citra satelit

- Menampilkan trajektori sebaran asap melalui system menu pada jendela brightness level.

- Memilih menu vert 5 (traj) bersamaan dengan tombol ctrl pada keyboard, kemudian terlihat hasil arah sebaran trajektori asap yang dimulai dari titik awal berjalan hingga mengikuti keadaan kondisi pola angin pada model NWP.

Setelah mendapatkan hasil olahan citra satelit dengan menggunakan metode RGB dan trajektori sebaran asap menggunakan aplikasi SATAID GMSLPD, kemudian penulis melakukan pemetaan data hotspot tanggal 8-9 September 2015 untuk wilayah Sumatera dan Kalimantan dengan menggunakan aplikasi QGIS versi 2.8.2 dengan format data awal bentuk .txt. Hasil olahan dari data hotspot ini lalu disimpan dalam bentuk gambar dengan format .jpg.

\section{HASIL DAN PEMBAHASAN}

\section{Analisis Data Sinoptik}

Berdasarkan data pengamatan sinoptik dari beberapa Stasiun Meteorologi terpilih yang berada di wilayah Sumatera dan Kalimantan, terlihat pada tanggal 8 September 2015 terdapat sebanyak 2863 titik hotspot yang tersebar di kedua wilayah tersebut. Terlihat pada gambar (1), wilayah Kalimantan merupakan wilayah yang memiliki titik hotspot terbanyak dibandingkan wilayah Sumatera. Berdasarkan banyaknya hotspot yang terjadi pada bulan September 2015 mengakibatkan di sejumlah visibility di sejumlah wilayah di Sumatera dan Kalimantan menurun. Hal ini berdampak pada sektor transportasi pada khususnya. Rata-rata visibility yang tercatat hampir di bawah $5000 \mathrm{~m}$. Bahkan ada beberapa wilayah yang mencatat visibility mencapai $100 \mathrm{~m}$ yang dimulai dari jam 00.00 UTC sampai 03.00 UTC. 


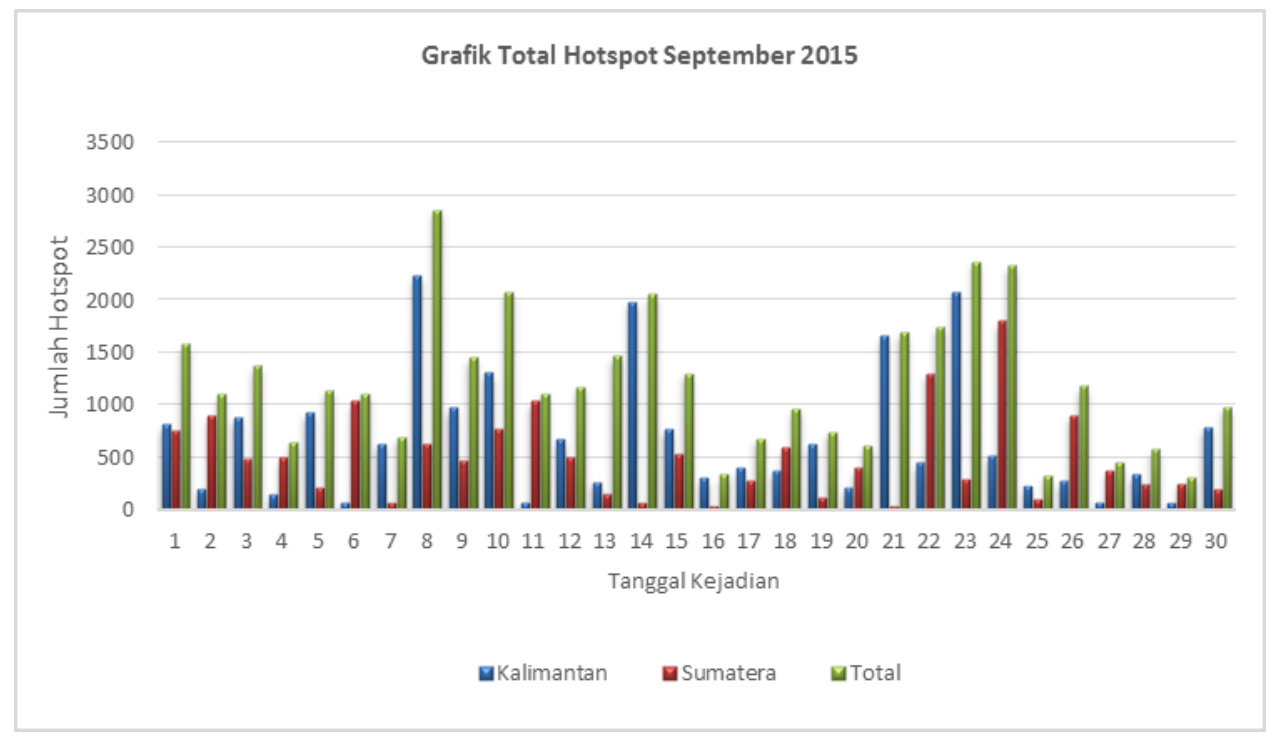

GAMBAR 1. Grafik Total Hotspot September 2015

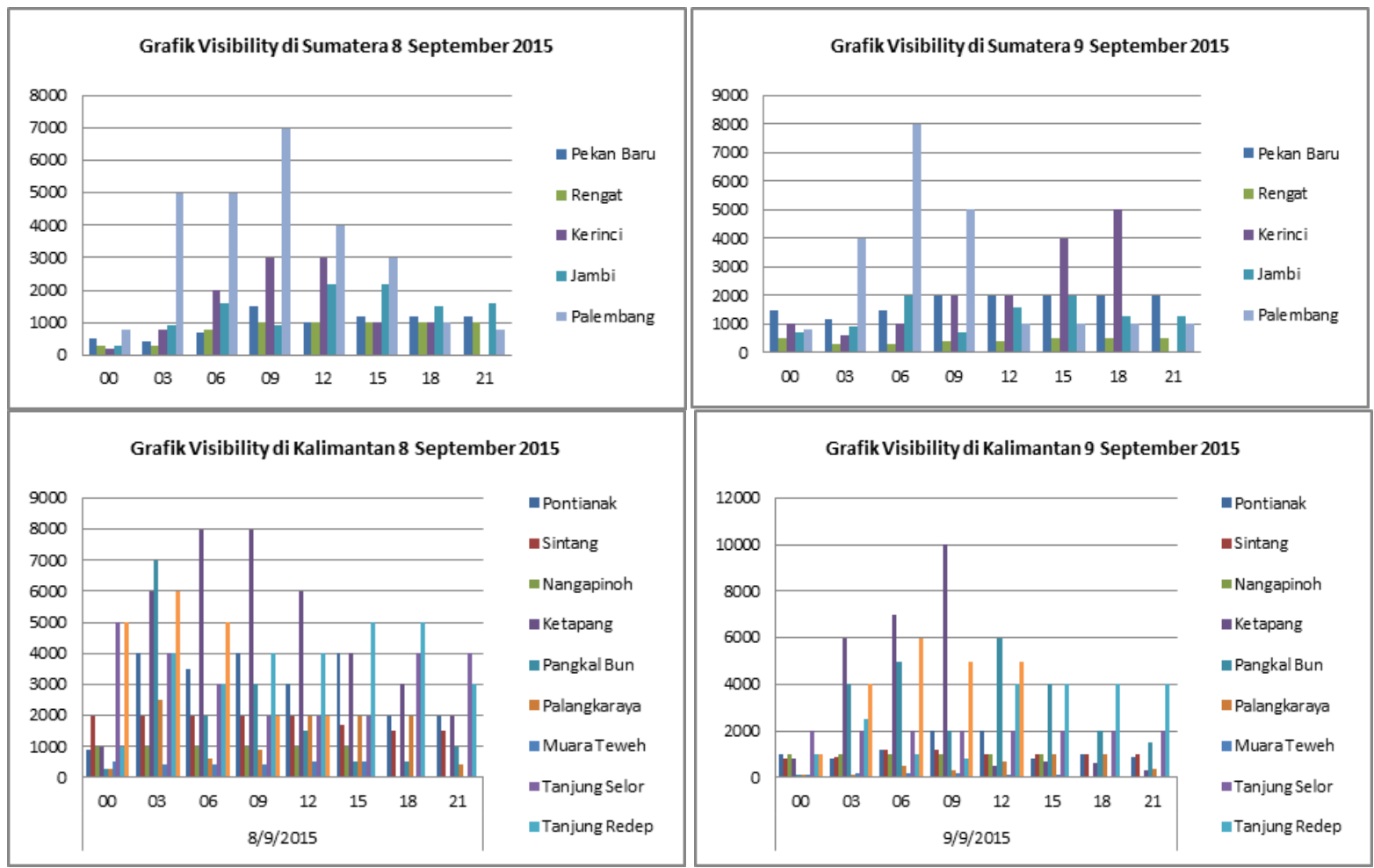

GAMBAR 2. Grafik Visibility (a) di Sumatera 8 September 2015, (b) di Sumatera 9 September 2015, (c) di Kalimantan 8 September 2015, dan (d) di Kalimantan 9 September 2015

\section{Analisis Sebaran Asap dengan Citra RGB Himawari 8}

Hasil pengolahan dari tampilan citra satelit dengan menggunakan metode RGB yang terlihat pada gambar 3 dan 4 terlihat adanya gumpalan berwarna kecokelatan yang dapat diindikasikan sebagai sebaran asap yang menutupi sebagian wilayah Sumatera dan Kalimantan. Dari gambar tersebut dapat terlihat untuk wilayah bagian barat Sumatera dan wilayah bagian tengah Kalimantan tertutupi oleh sebaran asap yang dimulai dari jam 00.00 UTC hingga jam 09.00 UTC. Setelah jam 09.00 UTC, 
sebaran asap mulai tampak tidak terlihat pada hasil olahan citra satelit tersebut, hal ini disebabkan oleh tidak adanya faktor radiasi matahari yang merupakan syarat utama sebagai sumber energi yang dipantulkan oleh objek di permukaan bumi terhadapp satelit. Hal ini berlaku untuk channel Visible pada satelit Himawari 8. Namun, berdasarkan data sinoptik masih ada beberapa stasiun Meteorologiyang melaporkan bahwa masih terjadi fenomena asap di beberapa wilayah. Berdasarkan hasil pengolahan trajektori citra satelit dengan menggunakan data GS menunjukkan angin di lapisan dekat permukaan bergerak dari arah tenggara - selatan menuju barat laut - utara di wilayah Kalimantan dan Sumatera. Arah gerakan angina ini berpotensi menyebabkan asap menyebar menuju wilayah barat laut - utara.

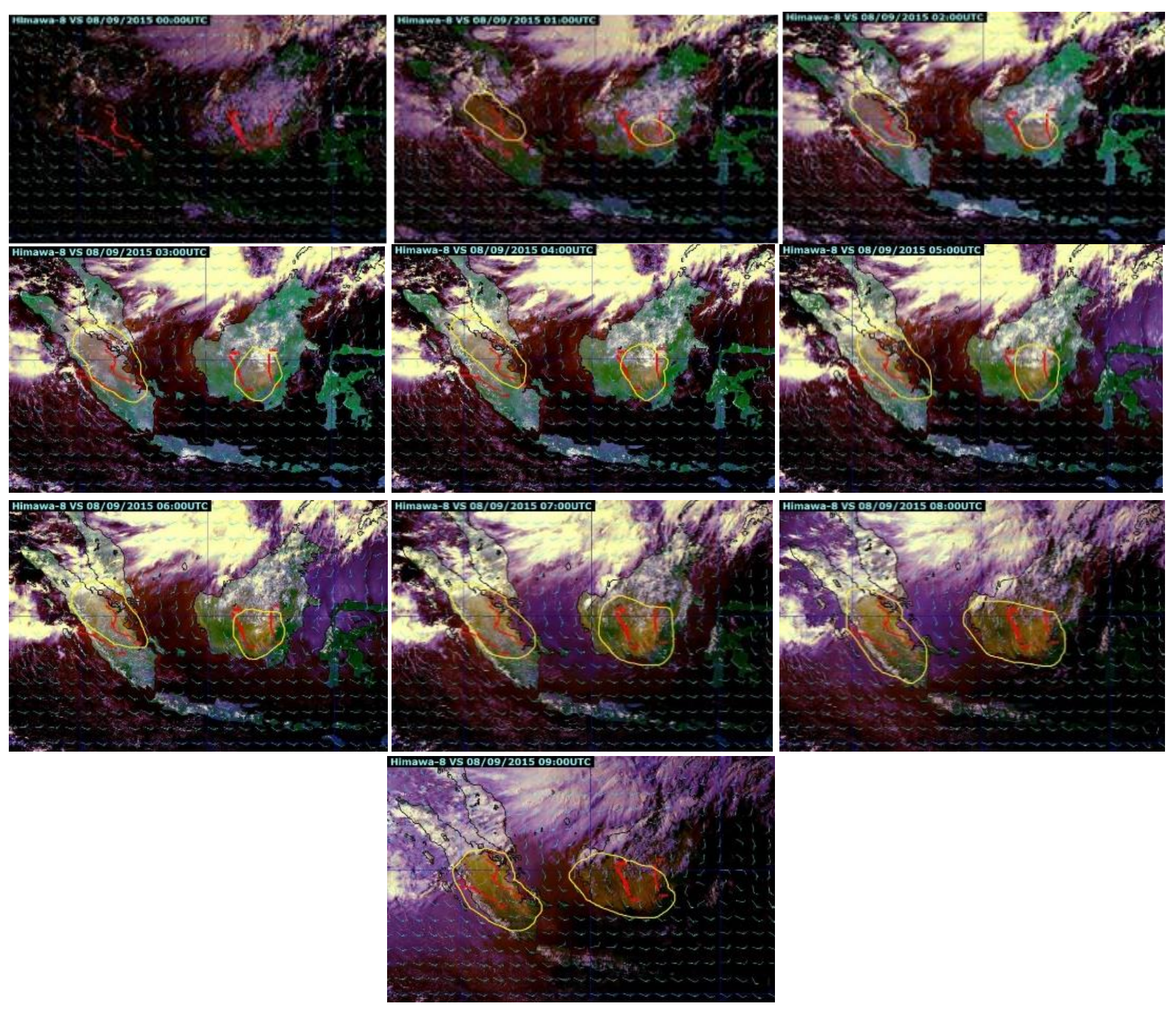

GAMBAR 3. Tampilan citra RGB satelit Himawari 8 dan Trajektori sebaran asap 8 September 2015 

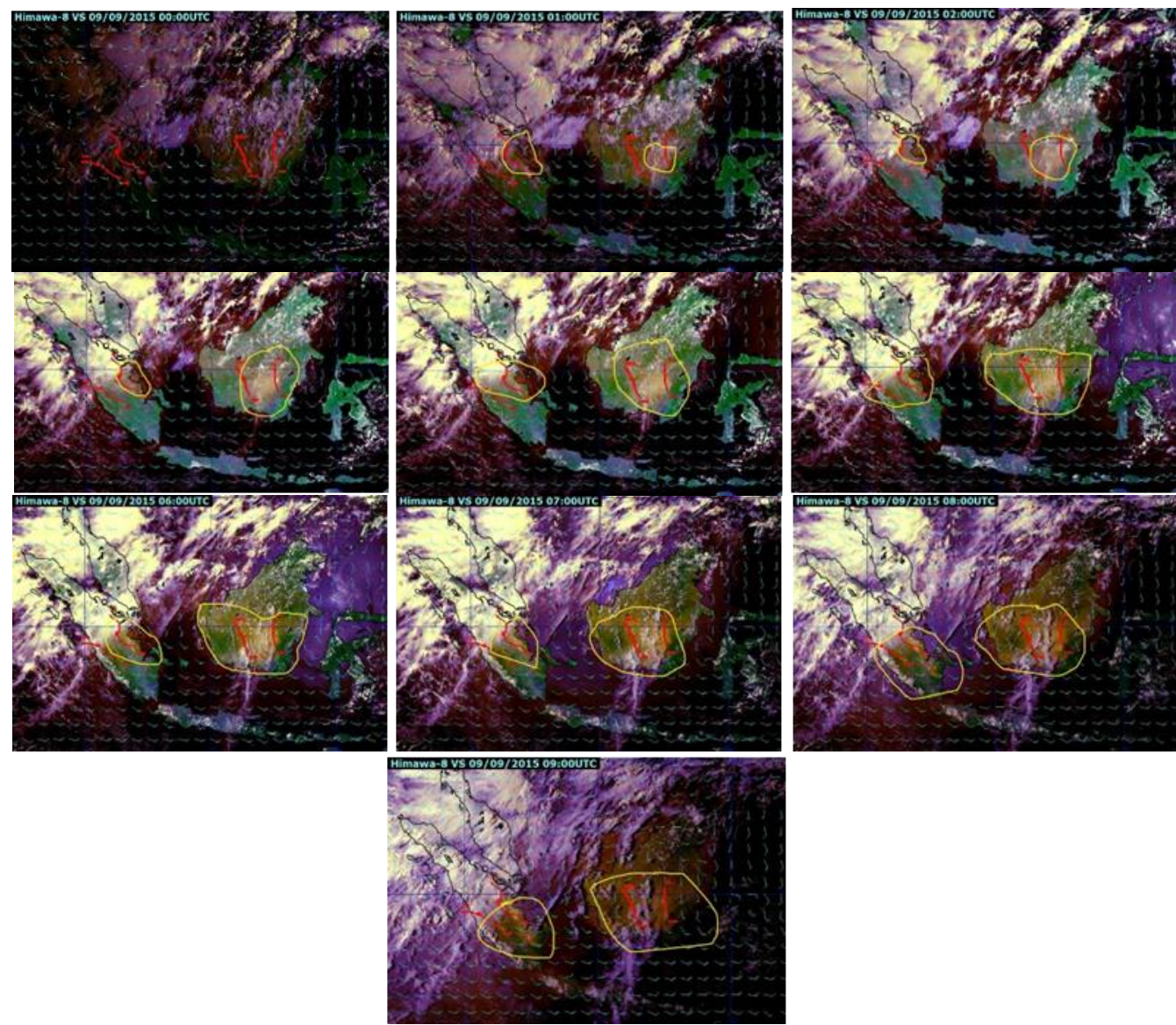

GAMBAR 4. Tampilan citra RGB satelit Himawari 8 dan Trajektori sebaran asap 9 September 2015

\section{Analisis Titik Api (Hotspot)}

Wilayah sebaran titik api dari citra satelit Terra/Aqua cukup mendukung hasil analisis citra satelit Himawari 8 dengan metode RGB untuk wilayah Sumatera dan Kalimantan. Berdasarkan hasil olahan kedua gambar diatas memberikan kesamaan pola terhadap hasil olahan dari citra satelit Himawari 8 dengan metode RGB. Berdasarkan pantauan gambar 5. terlihat bahwa sebagian besar titik api berada pada bagian barat pulau Sumatera dan Kalimantan bagian tengah.
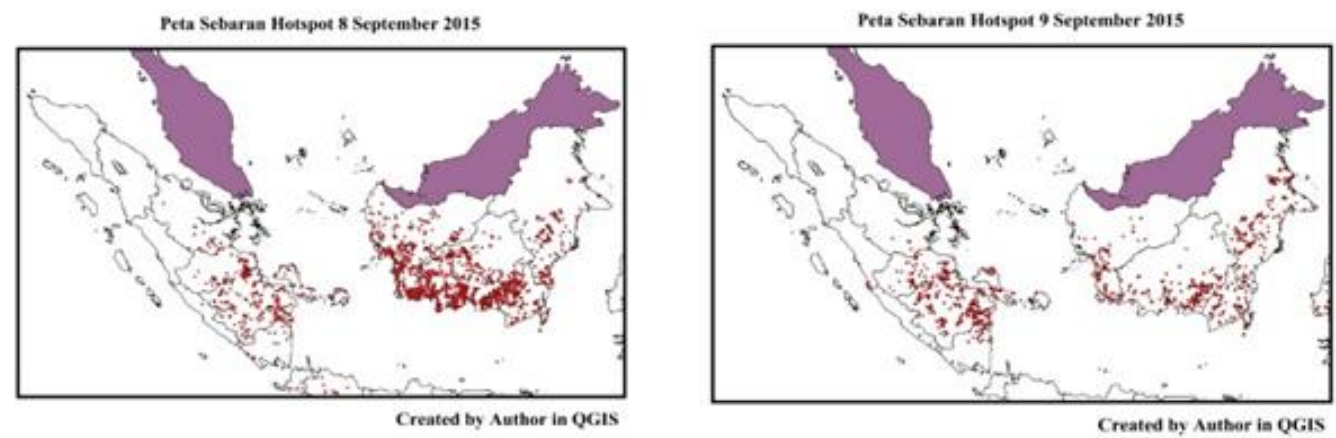

GAMBAR 5. Sebaran titik api citra satelit Terra/Aqua MODIS 8 dan 9 September 2015 


\section{SIMPULAN}

Berdasarkan hasil analisis data satelit Himawari-8 yang diolah dengan menggunakan aplikasi SATAID GMSLPD menunjukkan kesesuaian wilayah yang dominan tertutup asap dengan data sebaran hotspot pada tanggal 8-9 September 2015 di wilayah Sumatera dan Kalimantan. Gumpalan asap akibat kebakaran hutan ditandai dengan citra berwarna cokelat yang menutupi sebagian besar wilayah, khususnya Sumatera bagian barat dan Kalimantan bagian tengah mulai pada pukul 02.00 UTC. Hasil analisis dari satelit Himawari-8 juga diperkuat dengan laporan keadaan cuaca dari beberapa Stasiun Meteorologi di wilayah Sumatera dan Kalimantan. Trajektori citra satelit juga menunjukan angin di lapisan dekat permukaan di wilayah Sumatera bagian barat dan Kalimantan bagian tengah bergerak dari arah tenggara-selatan dan menyebar ke wilayah barat-utara. Penggunaan metode teknik RGB false color dari data satelit Himawari 8 dapat diterapkan untuk mendeteksi sebaran asap secara berkelanjutan. Sehingga memudahkan stakeholder dalam memantau dan mengetahui penyebaran asap akibat kebakaran hutan dan lahan.

\section{UCAPAN TERIMAKASIH}

Terima kasih penulis ucapkan kepada Kepala Sub-Bidang Pengelolaan Citra Satelit BMKG yang telah memberikan data satelit Himawari 8 merupakan data utama dalam penelitian ini. Penelitian ini tidak menutup kemungkinan masih banyak terdapat kekurangan sehingga diharapkan dapat memberikan kritik dan saran yang membangun.

\section{REFERENSI}

[1] Bahri, S. 2002. Kajian Penyebaran Kabut Asap Kebakaran Hutan dan Lahan di Wilayah Sumatera Bagian Utara dan Kemungkinan Mengatasinya dengan TMC. Jurnal Sains dan Teknologi Modifikasi Cuaca, 3(2):99-104.

[2] Dephut. 1997. Sejarah Kebakaran Hutan dan Lahan di Indonesia. Diakses pada http://www.dephut.go.id/neosis/indofire/index.php/indofire/info_detail/43.

[3] Kushardono, Dony. Kajian Satelit Penginderaan Jauh Cuaca Generasi Baru Himawari 8 dan 9. Inderaja. Vol.3 No. 5, Desember 2012.

[4] Pandjaitan, Bony S., dan Pandjaitan, Andersen. Pemanfaatan Data Satelit Cuaca Generasi Baru Himawari 8 Untuk Mendeteksi Asap Akibat Kebakaran Hutan Dan Lahan Di Wilayah Indonesia (Studi Kasus: Kebakaran Hutan Dan Lahan Di Pulau Sumatera Dan Kalimantan Pada Bulan September 2015). Seminar Nasional Penginderaan Jauh (2015) Pp. 636-6512009.

[5] Rani, Nurhastuti Anjar. 2016. Identifikasi Sebaran Asap Melalui Metode RGB Citra Satelit Himawari 8 (Kasus: Kebakaran Hutan di Sumatera dan Kalimantan 15 September 2015). Prosiding Seminar Nasional Fisika UNPAD (2016).

[6] Rianawati, F. (2005). Kajian Faktor Penyebab dan Upaya Pengendalian Kebakaran Lahan Gambut oleh Masyarakat di Desa Salat Makmur Kalimantan Selatan. Jurnal Hutan Tropis Borneo No.17, September 2005: 51-59.

[7] Shimizu, Akihiro. The Basis of RGB Image Composites. Meteorological Satellite Center Japan Meteorological Agency.

[8] Syaufina, L., dan Sukmana, A. (2008). Tinjauan Penyebab Utama Kebakaran Hutan di Daerah Danau Toba. Laporan Kajian Kebakaran Hutan Di Danau Toba. Centre of Forest and Nature Conservation Research and Development (CFNCRD) dan International Tropical Timber Organization (ITTO) PD 394/06 REV.1 (F). Bogor. 
Volume 2 Nomor 2,

Agustus 2017
p-ISSN: 2541-3384

e-ISSN: 2541-3392 